\title{
Honorio Delgado y la PSicología en DOS DE SUS LIBROS (PSICOLOGÍA Y LA PERSONALIDAD Y EL CARÁCTER)
}

\author{
Honorio Delgado and psychology in two of his \\ books (Psychology and personality and character)
}

\section{Ramón León ${ }^{2}$}

\section{Resumen}

Dos libros del psiquiatra peruano Honorio Delgado, Psicología (1933) y La personalidad y el carácter (1943), son analizadas en detalle en la presente comunicación ya que ambos nos permiten conocer la concepción de la psicología que tenía su autor. El primero, Psicología, escrito en colaboración con el filósofo Mariano Iberico, propone una psicología estrechamente vinculada a la filosofía, destacando el rol de la introspección y de la intuición. El segundo, La personalidad y el carácter, presenta los conceptos de Delgado acerca de la personalidad, y expone diversas teorías de la personalidad, destacando sobre todo las alemanas (Kretschmer, Jung, Spranger, entre otras).

Palabras claveS: Honorio Delgado, psicología, personalidad

\section{Abstract}

Two books written by the Peruvian psychiatrist Honorio Delgado, Psicología (Psychology, 1933) and La personalidad y el carácter (Personality and character, 1943), are analyzed in detail in this communication, since both allow us to know the author's conception of psychology. The first, Psicología, written in collaboration with the philosopher Mariano Iberico, proposes a psychology closely linked to philosophy, highlighting the role of introspection and intuition. The second, La personalidad y el carácter, presents Delgado's concepts of personality, and exposes various theories of personality, most notably the German ones (Kretschmer, Jung, Spranger, among others).

Key words: Honorio Delgado, psychology, personality.

1 Versión corregida y sustantivamente ampliada de la ponencia presentada con el título "Aportes de Honorio Delgado al desarrollo de la psicología contemporánea" en el Acto Académico "El legado de Honorio Delgado: Homenaje y Recuerdos a los 50 años de su fallecimiento" organizado por el Vicerrectorado Académico, la Cátedra Honorio Delgado y el Centro Universitario de Investigación y Desarrollo en Salud Mental de la Universidad Peruana Cayetano Heredia, el 26 de noviembre del 2019.

2 Universidad Ricardo Palma, Lima, Perú.

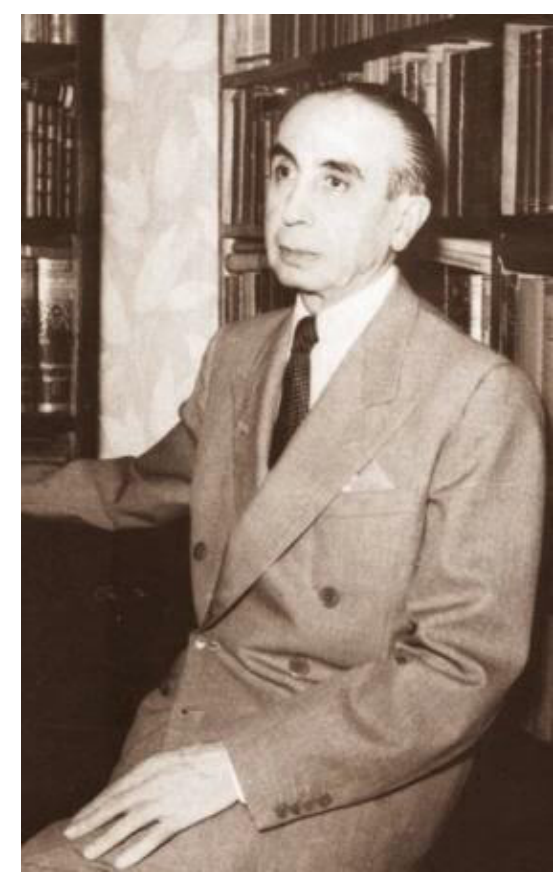

Honorio Delgado Espinoza (1892-1969)

\section{INTRODUCCIÓN}

En el escenario de la cultura y la ciencia peruanas del siglo XX la figura de Honorio Delgado aparece con claros $\mathrm{y}$, al mismo tiempo, múltiples perfiles. Científico y hombre de letras; investigador riguroso y pensador incisivo; autor de extensos tratados y sesudos estudios, como también de sofisticados ensayos sobre la cultura y sus artífices, y hasta de artículos periodísticos que han hecho historia (Delgado 1915); médico preciso 
en el diagnóstico, acertado en la estrategia terapéutica y vigilante en el seguimiento del caso. Difusor por último de avances de su especialidad, así como innovador de técnicas y creador de conceptos. Un scholar en el sentido más exigente del término (Alarcón-Guzmán 2008). Todo eso fue Honorio Delgado, a quien hoy recordamos al cumplirse 50 años de su partida a la eternidad.

La bibliografía sobre su obra y sus ideas es considerable y versa sobre todo en torno a su rol en la consolidación de la especialidad psiquiátrica en el Perú (Mariátegui 1989a) y su aporte teórico e investigatorio a esa rama de la medicina, así como su significativa contribución a la psicología como ciencia en nuestro país (Alarcón 2000, Chiappo 1957, 1992). Sus ideas en materia de psiquiatría han sido contrastadas con los avances de la especialidad (Alarcón-Guzmán 1982); su labor de difusión primero y de crítica después de las ideas freudianas también ha sido analizada (Mariátegui 1989b, Rey de Castro 1989, Ben Plotkin \& Ruperthuz Honorato 2017, León 2018). Su persona, su influencia en la cultura nacional, su labor magistral, han sido tratadas y continuarán siéndolo, con toda seguridad (Chiappo 1994).

Menos estudiadas han sido sus consideraciones filosóficas, presentes en algunos artículos (véase, a guisa de ejemplo, Delgado 1955) y capítulos de sus libros, como por ejemplo en De la cultura y sus artífices (Delgado 1961). Espera asimismo estudios detenidos su sostenido interés por las letras, concentrado sobre todo en la literatura alemana. La influencia de Baltasar Gracián, el gran conceptista aragonés, en el porte, la conducta y el ideario del maestro peruano sería también un tema digno de ser abordado.

Honorio Delgado estuvo al tanto de las corrientes psicológicas y filosóficas y de los desarrollos de su especialidad en el Viejo Continente, que hasta el inicio de la Segunda Guerra Mundial tenía la primacía en el mundo de las ideas. Mantuvo asimismo una constante actividad de lecturas, emprendió numerosos viajes de estudio, sostuvo sistemática correspondencia, y desplegó una búsqueda selectiva e intercambio de publicaciones, dictando muchas conferencias, organizando cursos de actualización, y dirigiendo (junto con J. Óscar Trelles) desde su fundación la Revista de Neuro-psiquiatría. Su primer interés era la psiquiatría, pero la psicología también estuvo entre sus temas preferidos.

En sus numerosos escritos es reconocible su atención por los temas psicológicos. No es algo incidental que su segunda tesis doctoral, la que le permitió optar el máximo grado académico en ciencias por la Universidad Nacional Mayor de San Marcos, tuviera por título Rehumanización de la cultura científica por la psicología (Delgado 1923). Ya entonces dedica a la ciencia psicológica cerca de 70 páginas en las que hasta el más distraído de los lectores reconocerá la importancia que le concede en el conjunto de las ciencias y en el mundo de la cultura, así como su familiaridad con la bibliografía especializada de aquella época, especialmente la europea, y muy en particular la alemana.

No trataremos en estas líneas del aporte de Honorio Delgado a la psicología porque eso, como ya se indicó, ha sido objeto de numerosos estudios. Solo esbozaremos aspectos relevantes de su obra para la psicología refiriéndonos a dos libros suyos: Psicología (Delgado \& Iberico 1933) y La personalidad y el carácter (Delgado 1943) (Figuras 1 y 2).

Ambos conforman el núcleo del aporte de Delgado a la psicología, que también 


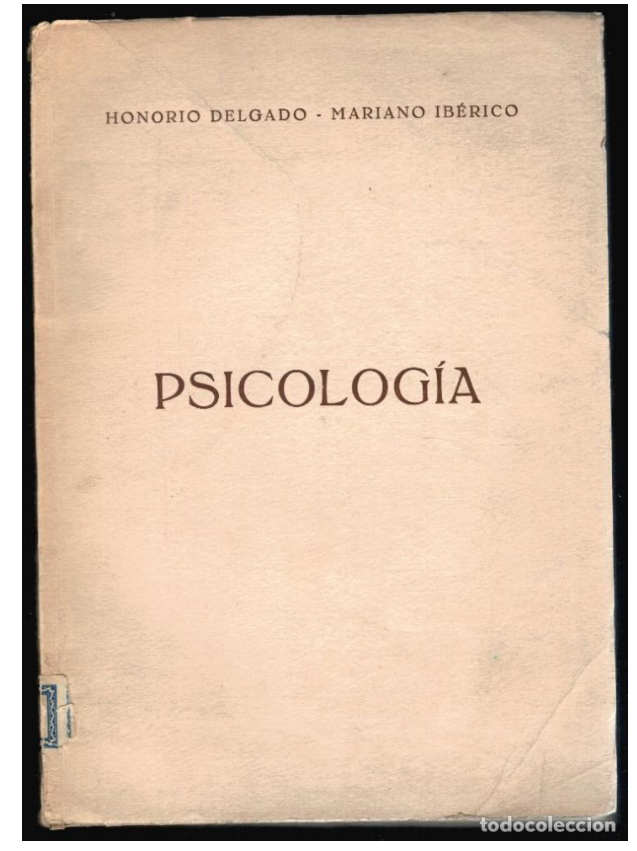

Figura 1

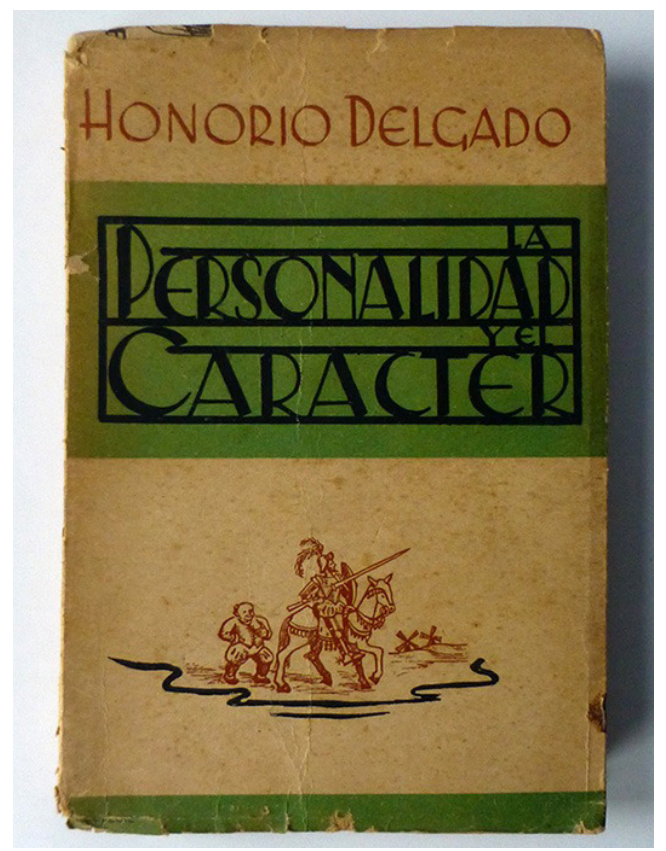

Figura 2

se manifestó, como hemos señalado, en numerosos artículos publicados en revistas nacionales que, por cierto, merecen al menos un breve comentario antes de entrar en materia.
Con fines de profundizar en el saber acerca del psiquismo y sistematizar la información proveniente de sus lecturas y experiencia clínica, el psiquiatra peruano publicó las siguientes contribuciones: "Psicología general y psicopatología de la percepción" (Delgado 1935), “Psicología general y psicopatología del pensamiento y la imaginación" (Delgado 1936a), y "Psicología general y psicopatología del sentimiento" (Delgado 1936b), "Psicología general y psicopatología de las tendencias instintivas" (Delgado 1938a), "Psicología general y psicopatología de la conciencia del yo" (Delgado 1938b), "Psicología general y psicopatología de la voluntad" (1939) y "Psicología general y psicopatología de la inteligencia" (1940). ${ }^{1}$

Se trata de artículos muy bien estructurados y sólidamente fundamentados en una amplia bibliografía. Pero detenidos y extensos como son, abordan solo aspectos circunscritos del acontecer psicológico (la inteligencia, los sentimientos, por ejemplo), en tanto que Psicología y La personalidad y el carácter constituyen presentaciones de conjunto de la ciencia psicológica el primero, y de dos conceptos centrales de ella el segundo.

En toda ciencia se requiere de obras que ofrezcan una visión panorámica y orientadora, y que recojan "lo no controvertido de las disciplinas, lo que se ha decantado como conocimiento aceptado y cabal, lo que puede transmitirse sin merma de la autoridad" (Lolas Stepke 1995, p. 8). La psicología no constituye una excepción. Desde sus inicios como ciencia

\footnotetext{
1 Por la fecha de su publicación (años 1935-1940), posterior a la aparición de Psicología, podemos suponer que Honorio Delgado buscó a través de la preparación de estos trabajos sistematizar toda la información que poseía sobre esos procesos psicológicos, integrando lo que la psicología normal y la psicopatología ofrecían sobre el particular. Mucho de este material sería empleado años después en la sección "Psicopatología general" de su Curso de psiquiatría (Delgado 1953a).
} 
han sido numerosos los tratados o manuales, algunos de ellos famosos por su condición de clásicos, y reimpresos y leídos a pesar del tiempo transcurrido. Tal es el caso de Principles of psychology, de William James (1890).

Psicología y La personalidad y el carácter son precisamente eso: obras que dan a conocer la primera los diferentes temas que constituyen el saber psicológico, y la segunda el intrincado terreno de la personalidad. Aún hoy (a pesar de los muchos años transcurridos desde su publicación y del avance que la psicología entre tanto ha experimentado) la lectura de ambas es una tarea que reditúa y cuya utilidad para fines docentes es grande. Así, por ejemplo, la descripción que Delgado lleva a cabo de las tipologías de Hipócrates, Kretschmer, Jung y Spranger puede ser empleada como material de trabajo en la formación de futuros psicólogos y psiquiatras.

\section{Psicología (1933)}

Psicología fue escrita al alimón por Honorio Delgado y Mariano Iberico (1892-1974), el filósofo peruano más importante del siglo XX. El título conciso guarda concordancia con la sobriedad de su formato, conservado a lo largo de sus repetidas ediciones. Sus autores fueron dos no-psicólogos que, vía la autodidáctica, se adentraron en la psicología. Nada sorprendente en un país como el nuestro, en el que nadie o casi nadie en los años treinta podía presentar credenciales de psicólogo, pues la especialidad de psicología como un ente autónomo en la estructura universitaria no existía.

Culminados los estudios superiores $\mathrm{y}$ en ausencia de centros especializados, los estudiosos peruanos emprendían el perfeccionamiento profesional y la exploración de disciplinas conexas a la suya siguiendo un largo proceso de autoformación.
El ejemplo paradigmático es sin duda José Carlos Mariátegui, quien no poseía estudios universitarios pero se hizo de una gran cultura en base a sus numerosas lecturas enriquecidas por la agudeza de su intelecto.

Sería asunto de interés explorar cómo se cumplía ese trabajo autodidáctico: ¿qué "estrategia" desarrollaba cada estudioso? La posibilidad de acceder a las novedades bibliográficas existía pero se veía dificultada por la distancia con respecto a las metrópolis científicas europeas y norteamericanas. Quien podía permitírselo se trasladaba a Europa o a los Estados Unidos, premunido de una beca de maestría o doctorado, o para viajes de estudio, en algunos casos con subvenciones estatales. Otros estaban al tanto de lo que ocurría en el exterior a través de la suscripción a revistas o la asistencia a conferencias.

Pero, el denominador común era el estudio permanente, la averiguación constante, la indagación proseguida de modo sistemático. Fue así que personas con formación en jurisprudencia cimentaron y nutrieron su vocación por la historia (Jorge Basadre), por la filosofía (Mariano Iberico) o la sociología (Mariano H. Cornejo). Julio C. Tello, formado en San Fernando, devino arqueólogo tras sus estudios de postgrado en Estados Unidos y Europa.

Honorio Delgado emprendió ese camino de la autodidáctica en materia de psicología. Influyó en él, sin embargo, Hermilio Valdizán, a quien siempre reconoció como su maestro, que durante sus años de estancia europea trabajó al lado de Sante De Sanctis, importante figura de la psicología y la psiquiatría italianas. El sistemático esfuerzo autodidáctico y la relación discipular con Hermilio Valdizán sentaron las bases del conocimiento que Honorio Delgado llegara a tener de la psicología. 
Son, ciertamente, muchos los libros psicológicos escritos por quienes no poseían una formación sistemática en esa disciplina: el así llamado padre de la psicología científica, Wilhelm Wundt, médico de profesión, forjó una monumental Völkerpsychologie (19001920). ${ }^{2}$ Más aún: en 1874 publicó el primer texto de psicología experimental: su Grundzüge der Physiologischen Psychologie (Wundt 1874) El creador del psicoanálisis, Sigmund Freud, médico asimismo, rabajó en lo que denominó un proyecto de psicología para neurólogos (Freud 1968), ensayo que tenía como objetivo articular un modelo que explicara lo que iba descubriendo desde un punto de vista psicológico, pero a partir de conceptos neurológicos (Hernández Ortiz 2014). Ludwig Binswanger, el destacado psiquiatra suizo, escribió asimismo un importante libro sobre psicología (Binswanger 1922). Y Karl Jaspers, dando fin a su actividad en la psicopatología e iniciando su fructuosa incursión en la filosofía, escribió Psychologie der Weltanschauungen (Jaspers 1919).

Eso fue lo que sucedió con Honorio Delgado quien, gracias al aprendizaje y progresivo dominio de las lenguas europeas fundamentales, amplió sus horizontes culturales, incluyendo dentro de ellos a la psicología. Lo mismo puede decirse de Mariano Iberico, que en 1912 obtuvo el grado de bachiller con una tesis sobre el carácter y en 1916 el doctorado en la Facultad de Filosofía y Letras con un trabajo sobre la filosofía de Henri Bergson (Iberico 1913, 1916).

En un comienzo atraído por la literatura y la poesía, Iberico reorientó sus intereses hacia la filosofía, y, al interior de ella por la psicología

2 Völkerpsychologie es un neologismo que puede ser traducido como "psicología social", "psicología cultural", "psicología histórica", y al que Navalles Gómez (2009) termina por calificar como "inasible". y la estética (Ramos Rau 2006). Su inclinación por el saber psicológico se expresó no solo en el libro escrito con Delgado sino en una serie de trabajos más (Reyes Álvarez 2014).

Unidos por la amistad, la comunidad de intereses académicos y la actividad académica cumplida en el claustro sanmarquino, Delgado e Iberico emprendieron en algún momento a finales de la década de los veinte e inicio de los años treinta la preparación de Psicología.

Los dos aportaron su amplia cultura y su formidable capacidad de trabajo al esfuerzo conjunto. Obviamente, hubo contribuciones individuales: la aportación de Delgado fue su conocimiento siempre actualizado de la medicina y las ciencias biológicas, así como su familiaridad con la filosofía alemana de la época, en tanto que Iberico concurrió a la tarea con su versación filosófica (especialmente en autores de lengua francesa) y su preparación jurídica.

De ese modo, en esta obra se conjugaron el conocimiento médico de un autor con el jurídico del otro, y el filosófico y el psicológico de los dos, concediéndole a Psicología un estilo especial. La exposición privilegia -como no podía ser de otro modo- lo psicológico, pero otorga el suficiente espacio y la necesaria consideración a los fundamentos biológicos del psiquismo humano; inclusive avanza con la cautela necesaria en la exploración filosófica de los fenómenos de la subjetividad. Todo esto a lo largo de sus 31 capítulos, caracterizados por estricto orden, lograda sistematización, y un lenguaje de elegante sobriedad que en algunos párrafos alcanza una expresividad con matices literarios.

Destacamos lo referido al estilo, algo que por lo general no suele ser tomado en cuenta en obras como la que estamos comentando, pues 
se supone que lo realmente importante son las ideas. Los hechos son los que mandan, se afirma, dado que ellos "hablan por sí solos". Eso es cierto, nadie lo niega en las ciencias exactas. Sucede sin embargo que la psicología, a la que hoy se la suele ubicar entre las ciencias naturales (Macho 2016), en muchas de sus áreas ofrece un saber que todavía es presuntivo, especialmente en lo que concierne a la personalidad, la motivación, la creatividad, y también a ese inmenso y angustiante mundo que es el de los trastornos psicológicos.

En esos dominios, en los cuales la oscuridad, la ambigüedad o la incertidumbre campean, se multiplican las teorías, unas plausibles y otras sobredimensionadas por una especulación que raya en la sinrazón, y en las que las palabras son empleadas sin mayor responsabilidad y los conceptos son trajinados sin medida.

En muy pocas ocasiones los psicólogos dedicamos algún minuto a examinar cómo se escriben los textos y se presentan las ideas, olvidándonos de que "el estilo es el hombre" como también de que somos criaturas espirituales desde el momento en que pasamos a ser seres verbales (Murdoch 2018). Todos sabemos que circulan textos de desgarbado estilo o de redacción casi críptica ${ }^{3}$, y otros en

3 Un ejemplo de lo primero lo constituyen los textos de Jacques Lacan: "Lacan makes difficult reading. No doubt about it", escriben Glynos \& Stavrakakis (2001: 685). Vincent (2019) ha dedicado todo un libro a analizar el estilo de este intelectual francés. En lo que se refiere a un estilo descuidado, podemos citar a una de las grandes figuras de la psicología dinámica, Alfred Adler. Su libro El carácter neurótico (Adler 1993), que es "la Biblia" de su doctrina y que contiene ideas e intuiciones sugerentes, se hubiera beneficiado notoriamente con una revisión estilística. Telegráfico por momentos, monotemático en su reiteración del sentimiento de inferioridad como la clave de la conducta humana, repetitivo en varios tramos, impreciso en las definiciones de más de algún concepto de crucial importancia, y superficial en donde la profundidad y la insistencia eran de esperar, El carácter neurótico se sigue reeditando a pesar de todo por la riqueza de sus sugerencias y la originalidad de sus intuiciones, provenientes de un clínico agudo como fue Adler (Kluy 2019).

En otros casos, el problema no estriba en el estilo ni en la los que lo abstruso muchas veces impresiona como inteligente o profundo.

Por eso es de importancia, no solo con fines didácticos, la forma en que las ideas y los hallazgos se exponen y se hilvanan en la disciplina psicológica. $\mathrm{Y}$ en eso Delgado e Iberico eran, no es necesario destacarlo pero recordarlo sí es oportuno, verdaderos maestros. El lenguaje preciso de la medicina y la rigurosidad del discurso jurídico (que tanto contacto tienen con la lingüística, Bordelois 2016), unidos a la rara sensibilidad de ambos autores para las connotaciones y alcances de los términos, así como la maestría en el arte de la redacción, se ponen de manifiesto en Psicología, cuya lectura puede hacerse en dos planos: en el académico por su contenido y en el estético por su estilo.

Como hemos dicho, conforman el libro 31 capítulos (ver tabla 1). Por lo general, en los textos modernos de psicología se comienza por la definición de ella y se continúa con su historia, para en seguida considerar los basamentos de la vida psicológica, la sensación y la percepción. No sucede eso con Psicología, en que los primeros capítulos están dedicados a consideraciones filosóficas sobre esta ciencia. De hecho, el primero tiene por título precisamente "Filosofía y psicología", e incluye tres acápites: "1. La ciencia y la filosofía. 2. Los temas de la filosofía. 3. Filosofía y psicología".

No sabemos cómo se organizó el trabajo. Nos

proposición de ideas teñidas de demasiada especulación, sino en la densidad misma de los términos que el autor emplea y en el manejo particular de conceptos. Sobre el particular permítasenos poner como ejemplo a Lev S. Vygotski y Jean Piaget. La lectura de sus trabajos demanda gran esfuerzo de concentración no solo por la complejidad de los temas abordados y la construcción estilística, sino también porque los autores, al parecer, escribían calamo currente. Ese era el caso de Jean Piaget, de productividad impresionante, quien, de acuerdo con lo que Parrat-Dayan (2010) nos informó, remitía lo escrito sin mayores retoques a la imprenta. 
falta para esto, lamentablemente, don Óscar del Pino Galarza, el leal y eficiente secretario personal de Honorio Delgado (AlarcónGuzmán 2014), quien habría podido decirnos mucho acerca de la disciplina de trabajo intelectual del gran psiquiatra peruano. Pero sí podemos suponer que la idea de escribir Psicología partió de él, pues había enseñado esa asignatura en la Facultad de Letras de la casa sanmarquina.

Los autores debieron autoasignarse la tarea de esbozar el contenido de algunos capítulos: ¿quién mejor que Delgado para el sétimo, dedicado a la teoría psicoanalítica, él, que se había carteado con Freud y había introducido el psicoanálisis en esta parte del mundo? ¿y quién mejor que Iberico para tratar el tema del carácter (capítulo 9)?

Trabajo en principio solitario y muchas veces cumplido en los fines de semana. Notas y esbozos de capítulos, búsqueda de textos apropiados en la biblioteca personal o en las institucionales, primeros borradores sometidos a repetidas correcciones, adiciones y supresiones de párrafos, confrontación de los textos a fin de evitar reiteraciones o afirmaciones contradictorias: todo esto debió cumplirse por parte de Delgado e Iberico.

Es de suponer, igualmente, que hubo permanentes reuniones $y$ revisiones hasta llegar a una versión satisfactoria. Lima, hacia los años treinta con unos 350 mil habitantes más o menos, era una ciudad sin muchos de los problemas que hoy la aquejan. Resultaba relativamente fácil programar reuniones semanales, quincenales, mensuales, no lo sabemos, en el domicilio de uno o de otro, o en los ambientes de la casona sanmarquina, hasta tener el manuscrito preparado. Y después, lo que nunca falta, la artesanía intelectual: cotejar las referencias, revisar los conceptos, afinar la redacción, así como anotar alguna crítica emitida al desgaire, o cierta sugerencia propuesta en una charla. De ese modo debe haberse gestado Psicología.

Psicología es uno de los tres grandes libros de psicología general escritos por autores peruanos o afincados en el Perú. Los otros dos son Introducción a la psicología experimental, de Walter Blumenfeld (1946), autor alemán que emigrara a nuestro país y permaneciera acá hasta su muerte, y Lecciones de psicología general, del filósofo José Russo Delgado (1962), aparecidos ambos ciertamente muchos años después y hoy día muy poco frecuentados.

Y, también es uno de los numerosos textos de psicología general provenientes de la pluma de autores latinoamericanos durante los últimos años del siglo XIX hasta poco más de la mitad del siglo $X X$.

En la tabla que sigue presentamos algunas de esas obras:

La mayoría de los autores de estas obras no eran psicólogos de profesión. Ingenieros y Mira y López eran médicos especializados en psiquiatría. Guerrero era filósofo. Larson Soudy fue un sacerdote profesor del Seminario Pontificio de Santiago de Chile, en tanto que el uruguayo Morey Otero era pedagogo y el cubano Bernal del Riesgo fue abogado. Los únicos que poseían una formación sistemática en psicología eran Blumenfeld, que se había doctorado bajo la dirección de Carl Stumpf; Mercedes Rodrigo y Waclaw Radecki, ambos discípulos de Edouard Claparède. El uruguayo Vaz Ferreira, intelectual de reconocimiento internacional, era abogado y filósofo.

Pero volvamos a la obra que estamos comentando.

Para Delgado e Iberico hay una vinculación irrenunciable entre la psicología y la filosofía, 
si bien formulan una apreciación que merece ser transcrita:

la psicología es una disciplina independiente, en el sentido de que confronta la experiencia de la vida psíquica sin la interposición de supuestos metafísicos, pero es una disciplina filosófica por la naturaleza particular de esa experiencia y, como la sociología y la historia, tiende a estudiar el ser del hombre como un todo, en lo que tiene de determinable para el conocimiento empírico (p. 20)

Hay asimismo una valoración muy sobria (por decir lo menos) de las posibilidades del método experimental:

La psicología experimental de laboratorio, por su misma naturaleza, limita la observación a fenómenos aislados, simplificados y condicionados artificialmente; excluye lo más genuino de la vida mental: la espontaneidad, las relaciones de conjunto, la continuidad configurativa y la fisonomía anímica individual. Lo que acontece en la vida real, lo que no se puederepetir a voluntad, lasemocionesintensas y los sentimientos diferenciados, los estados de ánimo caprichosos, las preocupaciones, los anhelos, las incertidumbres, los conflictos, etc., que nacen con las vicisitudes del existir en la arena del mundo, y cuya trama se enlaza con las realizaciones del destino personal -todo eso, y mucho más-, queda fuera del alcance de la psicología de laboratorio (p. 37).

En la parte final del capítulo 3, "Métodos de la psicología", del cual hemos transcrito este párrafo, los autores proponen una definición de psicología experimental sui generis:

Para terminar este capítulo, haremos notar que

Tabla 1: Capítulos de Psicología.

\begin{tabular}{|c|c|}
\hline 1. Filosofía y psicología & 17. Los estados afectivos sensoriales \\
\hline 2. Objeto de la psicología & 18. La emoción \\
\hline 3. Métodos de la psicología & 19. La inclinación y la pasión \\
\hline $\begin{array}{l}\text { 4. Caracteres principales de la actividad } \\
\text { consciente }\end{array}$ & 20. Concepto y extensión de la vida intelectual \\
\hline 5. Psicología y fisiología & 21. La sensación \\
\hline 6. La vida mental extraconsciente & 22. La percepción exterior \\
\hline $\begin{array}{l}\text { 7. Interpretación psicoanalítica de la vida } \\
\text { anímica }\end{array}$ & 23. La memoria \\
\hline 8. La conciencia del yo y la personalidad & 24. La asociación de las ideas \\
\hline 9. El carácter & 25. La abstracción y la generalización \\
\hline 10. Concepto y extensión de la vida anímica & 26. El juicio \\
\hline 11. El instinto & 27. El razonamiento \\
\hline 12. La expresión & 28. La imaginación \\
\hline 13. El hábito & 29. La inteligencia \\
\hline 14. La atención & 30. El espíritu objetivo y la actividad anímica \\
\hline 15. La voluntad & 31. La psicología social \\
\hline 16. Concepto y extensión de la vida afectiva & \\
\hline
\end{tabular}


es erróneo considerar como "experimental" solo a la psicología de laboratorio: es experimental toda psicología efectiva, todo método que permita una buena descripción, un análisis, una caracterización o una interpretación de la experiencia vivida y de las disposiciones anímicas; y además que no se concibe la psicología de laboratorio sin la existencia de la psicología general y empírica (p. 38).

Para los autores, las principales adquisiciones del saber respecto a la naturaleza humana psicología de primera mano- se alcanzan por la intuición y la interpretación fina y certera de espíritus particularmente dotados: grandes místicos, poetas, novelistas y moralistas, raros filósofos, historiadores y médicos (p. 38),

Estas afirmaciones hoy suenan anacrónicas y no sorprende que eso suceda, porque los contenidos de textos y tratados de cualquier rama del saber son superados con el paso del tiempo por los avances y nuevos desarrollos que tienen su origen en la investigación y la reflexión: ¿quién lee hoy, salvo aquellos interesados por la historia de la psiquiatría, el -en su momento muy valorado- Lehrbuch der Psychiatrie, de Emil Kraepelin (1883, con el título original de Compendium der Psychiatrie) o alguno de los libros -permanentemente reeditados mientras estuvo en vida- de Wilhelm Wundt, el así llamado padre de la psicología experimental?

Qué duda cabe asimismo de que, en efecto, muchas intuiciones fructuosas acerca de la vida psicológica han sido expresadas de modo magistral a través de obras literarias o de meditaciones filosóficas. Con Nietzsche, por ejemplo, se inicia lo que se suele llamar la era de la sospecha, dado que este filósofo enfatiza la presencia de fuerzas irracionales en la determinación de nuestra conducta, fuerzas que sin embargo se "disfrazan" de motivos plausibles. Lo mismo podría decirse de las reflexiones contenidas en las obras de moralistas como La Rochefoucauld, Chamfort, Vauvernages y de Rivarol.

Un rasgo singular de esta obra en su condición de libro de psicología general, es la inclusión de un capítulo dedicado al psicoanálisis. El capítulo 7 lleva por título "Interpretación psicoanalítica de la vida anímica", y abarca los siguientes acápites: "1. Indicación histórica. 2. Sentido psicológico de los olvidos, equívocos, actos fallidos, etc. 3. Interpretación de los sueños. 4. Los planos de la vida mental y sus relaciones dinámicas: el conflicto psicológico. 5. Los impulsos instintivos. 6. El principio del placer y el de la realidad: la sublimación. 7. Los complejos ideoafectivos".

Los autores señalan que en este capítulo se exponen "los resultados más fructuosos y menos objetables de la aplicación del método psicoanalítico, evitando la crítica de los puntos débiles de la teoría", pero vuelven en el capítulo 19, "La inclinación y la pasión", esta vez sí para cuestionar la concepción psicoanalítica de la vida mental, "distinta del puro método psicoanalítico" (p. 188).

El saber psicológico experimenta grandes cambios, y ha alcanzado tal nivel de crecimiento y diversificación que es absolutamente imposible tener una visión de conjunto. El generalista, aquel que podía moverse por los diferentes ámbitos del saber psicológico y opinar cosas fundamentadas en varios de ellos, ha desaparecido, cediendo su lugar definitivamente al experto en una esquina del saber, el especialista. Hay tantas especialidades y subespecialidades en la psicología, que en realidad cada una de ellas podría avanzar autónomamente (y de hecho lo hace) sin tomar en cuenta lo que ocurre en otras (RamosArenas 2016). 
Tabla 2: Algunos libros de psicología general publicados por autores latinoamericanos desde fines del siglo XIX hasta 1970

\begin{tabular}{|c|c|c|c|c|}
\hline Título & Autor & $\begin{array}{l}\text { Año de } \\
\text { edición }\end{array}$ & Lugar de edición & Editorial \\
\hline $\begin{array}{l}\text { Curso expositivo de } \\
\text { psicología elemental. }\end{array}$ & $\begin{array}{l}\text { Carlos Vaz Ferreira } \\
(1872-1958)\end{array}$ & 1897 & Montevideo & $\begin{array}{l}\text { Imprenta Artística Juan } \\
\text { Dornaleche y Ramos, } 255 \\
\text { pgs. }\end{array}$ \\
\hline Curso de psicología & $\begin{array}{l}\text { Enrique José Varona } \\
(1849-1933)\end{array}$ & 1905 & Habana & $\begin{array}{l}\text { Librería e Imprenta La } \\
\text { Moderna Poesía, } 565 \text { pgs. }\end{array}$ \\
\hline Psicología & $\begin{array}{l}\text { Ubaldo Romero } \\
\text { Quiñónez }\end{array}$ & 1909 & Guadalajara & Tip. La Región, 120 pgs. \\
\hline Principios de psicología & $\begin{array}{l}\text { José Ingenieros } \\
(1877-1925)\end{array}$ & 1911 & Buenos Aires & J. Rosso y Cía. \\
\hline Psicologia & Martin Dedeu & 1912 & Buenos Aires & $\begin{array}{l}\text { Edit. José Tragant, } \\
\text { XII+279 pgs. }\end{array}$ \\
\hline Pincipios de psicología & $\begin{array}{l}\text { Bernardo J. Gastélum } \\
(1886-1981)\end{array}$ & 1920 & México & Helios, 422 pgs. \\
\hline Psicología & J. Pastracoin & 1924 & Buenos Aires & $\begin{array}{l}\text { Edit. A García Santos, } 358 \\
\text { pgs. }\end{array}$ \\
\hline $\begin{array}{l}\text { Apuntes de psicología } \\
\text { experimental }\end{array}$ & $\begin{array}{l}\text { Oscar Larson (1892- } \\
1974)\end{array}$ & 1926 & Santiago & Imprenta Chile, 272 pgs. \\
\hline Apuntes de psicología & S. Campana & 1927 & Panamá & $\begin{array}{l}\text { Editorial Benedetti } \\
\text { Hermanos, } 139 \text { pgs. }\end{array}$ \\
\hline $\begin{array}{l}\text { Elementos de psicología. } \\
\text { Antecedentes filosóficos e } \\
\text { históricos de la psicología }\end{array}$ & $\begin{array}{l}\text { Sebastian Morey } \\
\text { Otero (1894-1939) }\end{array}$ & 1931 & Montevideo & Claudio García, 317 pgs. \\
\hline Psicología & $\begin{array}{l}\text { Honorio Delgado } \\
(1892-1969) \& \\
\text { Mariano Iberico } \\
(1892-1974)\end{array}$ & 1933 & Lima & Edición de los autores \\
\hline Iniciación a la psicología & $\begin{array}{l}\text { Alfonso Bernal del } \\
\text { Riesgo (1902-1975) }\end{array}$ & 1936 & La Habana & $\begin{array}{l}\text { Imprenta F. Sabin y Co., } 2 \\
\text { vols. }\end{array}$ \\
\hline Lecciones de psicología & $\begin{array}{l}\text { Manuel Riquelme } \\
\text { (1885-1961). }\end{array}$ & 1936 & Buenos Aires & Ángel Estrada, 384 pgs. \\
\hline Lecciones de psicologia & $\begin{array}{l}\text { Gregorio } \\
\text { Fingermann (1890-?) }\end{array}$ & 1937 & Buenos Aires & El Ateneo, 278 pgs. \\
\hline
\end{tabular}


Psicología

Psicología

Curso de psicologia

Sicología

Apuntes de psicología para

la enseñanza secundaria y

normal

Breviario de psicología

Introducción al estudio de la

psicología

Tratado de psicología

general. Un estudio de la

conducta humana

Tratado de psicología

Los fundamentos de la

psicología

Introducción a la psicología

experimental

Psicología

Psicología humana. Curso

panorámico

Introducción a la psicología

científica

Apuntes de psicología para

la educación secundaria y

normal

Psychologia
Juan Luis Guerrero

(1897-1958)

José María Pérez

Jordán B. Genta

Enrique Barboza

(1901-1967)

Luis B. Prieto

Figueroa

Adolfo Menéndez

Samara

(1891-1982)

Roberto Agramonte

(1904-1995)

Waclaw Radecki

(1887-1953)

Joao de Souza Ferraz

(1903-1988)

Walter Blumenfeld

(1882-1967)

Ignacio M. Orovio

Alfonso Bernal del

Riesgo

Oswaldo Robles

(1904-1969)

Luis Beltrán Prieto

Figueroa (1902-1993)

Jacobus Gustavus

Morán
1941

1942

1946

1946

1939

1940

1940

1940

1940

México

México

Bogotá

1942-1943 La Habana

1943

1944

1946

Lima

1948

1948

1949
Buenos Aires

Buenos Aires

Buenos Aires

Habana

México

México

México
Losada, 382 pgs.

Edit. Centro, 228 pgs.

Kapelusz

Librería Miranda, 160 pgs.

Editorial Morelos, 400 pgs.

Antigua Librería Robredo, 318 pgs.

Universidad Nacional de

Colombia, 126 pgs.

Cultural, 2 vols.

Peuser, 428 pgs.

Americalee

Editorial Marcos Sastre, 158 pgs [texto adaptado a los programas de los colegios nacionales]. Imprenta Universidad de la Habana Porrúa, 327 pgs.

Ediciones Morelos

Editorial Buena Prensa, 2 vols. 


\begin{tabular}{|c|c|c|c|c|}
\hline Psicologia experimental & Casimiro Tronco & 1950 & $\begin{array}{l}\text { Rio Grtande do } \\
\text { sur }\end{array}$ & Edit. Pallotti, 335 pgs. \\
\hline $\begin{array}{l}\text { Elementos de psicología } \\
\text { aplicada para el sexto año }\end{array}$ & & & & \\
\hline $\begin{array}{l}\text { de las escuelas normales de } \\
\text { acuerdo con el programa en } \\
\text { vigor. }\end{array}$ & Daniel Ruiz & 1951 & Buenos Aires & Editorial Estrada, 186 pgs. \\
\hline Nociones de psicología & $\begin{array}{l}\text { Oscar Miró Quesada } \\
(1884-1981)\end{array}$ & 1953 & Lima & $\begin{array}{l}\text { Ministerio de Educación } \\
\text { Pública, } 244 \text { pgs. }\end{array}$ \\
\hline Psicología & $\begin{array}{l}\text { Sebastián Sánchez } \\
\text { Rincón }\end{array}$ & 1954 & Montevideo & Edit. Medina, 200 pgs. \\
\hline $\begin{array}{l}\text { Curso elemental de } \\
\text { psicología }\end{array}$ & $\begin{array}{l}\text { José María. } \\
\text { Velásquez Portuondo } \\
\text { (1901-?) }\end{array}$ & 1954 & La Habana & Minerva, 6ta. edición \\
\hline $\begin{array}{l}\text { Lecciones de psicología } \\
\text { general }\end{array}$ & $\begin{array}{l}\text { José Russo Delgado } \\
(1917-1997)\end{array}$ & 1962 & Lima & $\begin{array}{l}\text { Universidad Nacional } \\
\text { Mayor de San Marcos. }\end{array}$ \\
\hline Tratado de psicología & $\begin{array}{l}\text { Samuel Vargas } \\
\text { Montoya }\end{array}$ & 1963 & México & Porrua, 496 pgs. \\
\hline Psicología general & Ignacio Burk & 1964 & Caracas & $\begin{array}{l}\text { Editorial Divelli, 2da. Ed, } \\
437 \text { pgs. }\end{array}$ \\
\hline Introducción a la psicología & Luis María Ravagnan & 1965 & Buenos Aires & Kapelusz, 232 pgs. \\
\hline Sintesis de psicología general & $\begin{array}{l}\text { Josué Sosa } \\
\text { Castellanos }\end{array}$ & 1965 & México & Porrúa, 544 pgs. \\
\hline Elementos de psicologia & $\begin{array}{l}\text { Guillermo Pérez } \\
\text { Enciso }\end{array}$ & 1966 & Caracas & Doña Bárbara \\
\hline Psicología general & $\begin{array}{l}\text { José María Pérez } \\
\text { Izquierdo }\end{array}$ & 1966 & México & Porrúa, 314 pgs \\
\hline Psicología general & E. Meneses Morales & 1967 & México & Porrúa \\
\hline $\begin{array}{l}\text { Introducción general a la } \\
\text { psicología contemporánea }\end{array}$ & $\begin{array}{l}\text { Ricardo G. Mandolini } \\
\text { Guardo }\end{array}$ & 1967 & Buenos Aires & Ciordia, 492 pgs. \\
\hline Manual de psicología general & $\begin{array}{l}\text { Emilio Mira y López } \\
(1896-1964)\end{array}$ & 1969 & Buenos Aires & Kapelusz, 299 pgs. \\
\hline Psicología en ejemplos & $\begin{array}{l}\text { M. Rodríguez } \\
\text { Estrada }\end{array}$ & 1970 & México & Trillas, 306 pgs. $3^{\text {a }}$. ed \\
\hline
\end{tabular}

Fuente: Díaz Díaz \& Santos Escudero (1982). 
De otra parte, el avance de las neurociencias plantea desafíos a la psicología que obligan a que los psicólogos reformulen muchos de sus conceptos o comiencen a entenderlos de un modo distinto. La información que día a día van acumulando los neurocientistas es de tal envergadura que no puede ser más ignorada.

Y, por último, el mundo de hoy es de tal complejidad que muchos de sus problemas demandan enfoques inéditos o en algunos casos, el retorno a procedimientos y formas de análisis habituales en el pasado que, en medio de la algarabía y el entusiasmo alimentados por los avances tecnológicos o novedosas proposiciones teóricas, fueron dejados de lado.

En ese contexto, ¿qué nos ofrece Psicología?

Una visión filosófica de la ciencia psicológica, que podrá considerarse anticuada, porque también en la filosofía ha habido importantes desarrollos en todo lo que va del siglo XX (Garrido et al. 2019), pero que igual rescata lo que siempre ha estado en el centro de las preocupaciones del ser humano: ¿quién soy? ¿cómo puede conocerse a sí mismo?

Esas son preguntas que acompañan al hombre desde que tomó conciencia de su condición humana, y lo acompañarán hasta que desaparezca de la faz de la Tierra.

Son muchos los psicólogos que piensan que la psicología tiene poco que ver con la filosofía, parecer que encuentra refuerzo en los textos modernos de la especialidad, en los cuales las referencias a la filosofía son casi nulas. La historia de la psicología enseña sin embargo cuánto debe esta a la "reina de las ciencias" y cómo la dimensión filosófica aparece en toda su magnitud después de un breve análisis de los temas psicológicos.
De otro lado, Delgado e Iberico apuestan por la introspección como la via regia del conocimiento de la propia condición. Y no cabe duda que esa es a pesar de todo la vía. Los experimentos psicológicos, inclusive los más rigurosos (que los hay), informan sobre las particularidades de la especie humana, pero no pueden decir nada sobre la subjetividad de cada cual, una terra incognita a la que solo se puede acceder desde la reflexión íntima.

Menospreciada por buen número de cultores de la psicología lo cierto es que, al final, el psicólogo clínico, el psicólogo social, el psicoterapeuta, dependen de ella para obtener información de primera mano sobre lo que viven y vivencian las personas. La psicología, a pesar de su innegable desarrollo, no puede aún (y tal vez nunca lo consiga) prescindir de ella.

Vista como un fenómeno misterioso y elusivo en la época en la cual Psicología apareció, la intuición apenas era objeto de estudio por parte de los psicólogos. Estaban por cierto los trabajos de Wolfgang Köhler (1921), pero suponer que ellos podrían ser la base para una explicación de la intuición era algo bastante audaz en ese momento.

Los lectores profundamente positivistas de Psicología deben haber levantado las cejas ante la proposición de los autores de relievar el papel de la intuición.

Hoy las cosas han cambiado. La intuición es entendida y estudiada cada vez más como una forma de conocimiento inmediato (Gigerenzer 2008, Hogarth 2010, Kahnemann 2012) en que juega un rol decisivo lo que los psicólogos denominan el "inconsciente colectivo".

Obviamente, no toda intuición es necesariamente correcta, como también lo anota Kahnemann (2012). Peroen determinadas 
personas, en pensadores agudos y en literatos de fértil imaginación, la intuición es también una vía de ingreso a la vida psicológica. E igualmente lo es para el ciudadano común y corriente, que muchas veces toma decisiones en base a ella.

No menos importante nos parece la referencia al conocimiento psicológico presente en las grandes obras literarias, que siempre han demostrado ser una inagotable fuente de conocimiento acerca de las excelencias y las carencias inherentes a la condición humana. Agradaría, sin duda, a Honorio Delgado saber que al acierto de proponer la lectura de "los grandes literatos que sufren y estudian sus flaquezas" (Delgado 1953, p. 33), como Dostoievski, Leopardi y Baudelaire, se suma el hecho de que las neurociencias encuentran en algunas obras literarias de ayer y de hoy sorprendentes adelantos e intuiciones de sus hallazgos (Quian Quiroga 2012, Lehrer 2010, Álvaro 2016, Piccolino 2019).

\section{LA PERSONALIDAD Y EL CARÁCTER (1943)}

Personalidad, Motivación, Inteligencia y Desarrollo son cuatro conceptos en torno a los cuales gira la mayor parte del conocimiento psicológico. De allí el gran número de libros y artículos que tratan de ellos. Delgado abordó el primero en La personalidad y el carácter, libro presentado como una "exposición, a la vez densa y panorámica, de los conocimientos y problemas de la personalidad y el carácter".

Esta obra, que ha alcanzado cinco ediciones ${ }^{4}$, es la solitaria contribución peruana al estudio de la personalidad, pues no se ha publicado otro libro de esta índole en nuestro medio. ${ }^{5}$

4 Hemos trabajado con la edición del 2006.

5 Explicable este hecho teniendo en cuenta el gran número de teorías existentes así como las crónicas carencias bibliográficas de las que se adolece en nuestro medio.
Así como en Psicología, también en esta obra se pone de manifiesto el esfuerzo sistematizador de Honorio Delgado, algo que debe destacarse, pues quienes se acercan al estudio de los conceptos antes mencionados se enfrentan (tanto hoy como ayer) a una verdadera maraña conceptual, que solo puede ser superada con un conocimiento detenido de la bibliografía existente y un criterio ordenador.

Tres capítulos conforman la obra en su versión final: 1. La personalidad anormal. 2. La personalidad anormal; y 3. La personalidad y la crisis de la cultura.

La Tabla 3 presenta las secciones de cada uno de estos tres capítulos

Es necesario antes de tratar en detalle este libro hacer una breve referencia al contexto. En el año de su publicación, la Segunda Guerra Mundial seguía su curso devastador. La ciencia y la industria de los países beligerantes estaban concentradas en satisfacer las demandas militares. Muchos de los psiquiatras y psicólogos se habían integrado a sus ejércitos nacionales para llevar a cabo tareas de su especialidad. Las comunicaciones entre los países se encontraban virtualmente interrumpidas: congresos científicos, reuniones académicas nacionales e internacionales, intercambio de información entre profesionales de diferentes países, o estaban suspendidos o enfrentaban numerosas dificultades.

Todavía hacia mediados de la década de los 30 la psicología alemana gozaba de preeminencia. Y también la psiquiatría germanoparlante, que había tenido su edad de oro con los aportes de Kraepelin, Freud, Jaspers, Jung y Kretschmer, cuyas ideas también habían influido en el estudio de la personalidad (Peters 2010). La llegada de Hitler al poder trajo consigo la emigración de muchos psiquiatras y psicólogos así como una orientación de la psicología y la 
psiquiatría a los intereses del régimen (véase Peters 1992, Stahnisch \& Russell 2018, Stock \& Schneider 2020). Quienes se mantuvieron al margen de la "nazificación" que ocurría en las universidades, prosiguieron en medio de dificultades con su trabajo, en el que los vínculos entre la filosofía y la psicología seguían siendo bastante estrechos (Geuter 1988).

Entre tanto, en los Estados Unidos la matematización y la experimentación en psicología predominaban en todas las universidades (si bien en los medios clínicos el psicoanálisis ganaba fuerza), así como el desarrollo de nuevos enfoques de la personalidad, fundamentadosenbuenamedida en datos provenientes de investigaciones con un fuerte componente estadístico, tomando distancia del concepto de carácter y de las connotaciones éticas del mismo (Nicholson 1998). La obra de Gordon Allport, Personality: a psychological interpretation (Allport 1937), constituyó un importante avance al proponer el estudio de los rasgos. Delgado conocía los trabajos del psicólogo norteamericano, pero el enfoque que prefería, por su detenido conocimiento de la psicología y la psiquiatría alemanas, era el tipológico, ampliamente desarrollado en el mundo germanoparlante. Eso explica que las teorías expuestas en $\mathrm{La}$ personalidad y el carácter sean las provenientes de ese ámbito lingüístico.

Señalemos además que al momento de publicarse La personalidad y el carácter se estaba todavía algunos años antes de que apareciera el trabajo de Erikson (1950), que ubicaría a la identidad como uno de los temas centrales en el estudio de la personalidad.

Delgado señala que "la personalidad es objeto de conocimiento de diversas disciplinas filosóficas" e indica que "la psicología que hoy se constituye y que nosotros tratamos de promover no solo es fenomenológica, estructural y de superficie, sino dinámica, genética, integral y práctica”.

Veamos la definición que propone de la personalidad:

definimos la personalidad como el sistema de las disposiciones individuales dominantes según el cual se ordena y manifiesta la vida anímica de cada sujeto en lo que respecta a su espontaneidad, a su impresionabilidad y a su modo de reaccionar distintivos, con cierto grado de coherencia y con mayor o menor conciencia e intención por parte del yo (Delgado 2006, pg. 3).

En las primeras cuatro secciones del primer capítulo el autor se extiende en aspectos teóricos. Es en la quinta sección en la cual el autor peruano se acerca a los temas que posteriormente Erikson trataría en detalle. En ese acápite, que lleva por título "Relaciones de la personalidad con el yo", se explaya:

En cierto modo, la personalidad tiene en el yo su centro, en el doble sentido de que (no sin limitaciones, a veces considerables) domina la perspectiva del modo de ser personal y de que ejerce influencia determinante sobre la actividad de éste. Yo me vivo a mi mismo como entidad constante y punto de referencia en medio del contenido mudadizo de mi experiencia, y yo también me vivo como agente determinativo de ciertas transformaciones que se operan en la economía de mi ser (p. 8).

Delgado profundiza sobre el particular y señala que las relaciones del yo con la personalidad tiene una serie de aspectos: el sentimiento de la personalidad ("... siempre algo vago, que se constituye y diferencia a lo largo de la vida, con periodos de equilibrio y periodos de inseguridad, con intensificaciones y debilitamientos, con ilusiones y falseamientos, tanto más auténtico cuanto más fundado en 
los efectos de la vida activa", la conciencia de los valores de la personalidad (en la cual "las vicisitudes de la existencia, sobre todo de la educación, en que la valoración -explícita o implícita- que hacen de nosotros los demás es a veces de incalculables consecuencias, incluso para la constitución del carácter"), el conocimiento de uno mismo ("tarea forzosamente imperfecta, con un margen de ilusión que nadie puede medir y cuyas ventajas y peligros escapan a la previsión"), $\mathrm{y}$, finalmente, el ideal de la propia persona ("producto de las aspiraciones más íntimas y de lo que admira sin reservas en materia de bienes subjetivos", cuya presencia "contribuye a organizar la actualidad de cada cual, por lo menos en situaciones particularmente importantes para la estima propia").

Concluye esta sección con una afirmación categórica:

La injerencia de la intención del yo en el funcionamiento de la personalidad se muestra de manera relevante en los actos de dominio de si, de disciplina, de vencimiento interior, de educación reflexiva. Con el ejercicio de la voluntad el sujeto determina la dirección de la actividad personal conforme a exigencias del espíritu o a modelos de conducta que requieren oponer resistencia a determinadas tendencias, especialmente a las de naturaleza sensual.

La lectura de las citas previas permite reconocer que Delgado propone en sus términos y en su momento lo que después Erikson denominará identidad.

Llegado el momento de exponer las teorías sobre la personalidad y el carácter, Delgado señala que "esbozamos solo algunas de las que se han mostrado realmente fecundas para la clasificación y comprensión de los hombres", anotando por último que "no consideramos las llamadas tipologías empíricas, fundadas en la averiguación estadística de valores o relativos a las diferencias de raza, sexo, profesión, posición social, etc."

Así, aparte de Hipocrates se exponen los sistemas tipológicos de Ernst Kretschmer, el de los hermanos Jaensch, el de Pfahler, el de Jung y el de Spranger. Como ya habíamos señalado, predomina el mundo alemán de la psicología. El tono es fundamentalmente expositivo, pero eso no es óbice para que proponga ideas propias.

Algo llamativo es el gran interés concedido a la obra de Nicolai Hartmann, destacado filósofo alemán, cuyas ideas aparecen en La personalidad y el carácter. Delgado sentía una profunda admiración por este pensado ${ }^{6}$, habiéndole dedicado un escrito (Delgado 1956).

Hartmann fue entre 1925 y 1950 una de las grandes personalidades de la filosofía alemana, cuyos libros, constantemente reeditados, trataban de la ontología, la epistemología, la ética y la estética (Cicovacki 2014), algo que contrasta con el olvido en que ha caído hoy día su obra.

Este pensador alemán es completamente desconocido para los psicólogos de nuestros días, orientados a un enfoque de la personalidad en el cual el trabajo experimental y la perspectiva matematizante ejercen una poderosa influencia. ${ }^{7}$ Es verdad: no era un experto en temas de personalidad ni mucho menos, pero en sus escritos se reconoce primero una sólida base de información científica,

6 Hartmann es más citado inclusive que Freud en este libro.

7 Pero además está el hecho de que la mayoría de trabajos suyos no ha sido traducida al inglés y, por lo tanto, los psicólogos angloparlantes no pueden conocer su obra (Fahrenberg 2015), en la cual si bien es verdad que ningún título está dedicado específicamente a la psicología, esta ciencia es tratada constan temente (Kessel 2019). 
incluyendo a las ciencias naturales ${ }^{8} \mathrm{y}$, además, la proposición de algunos planteamientos que sí fueron de interés para los psiquiatras y psicólogos de su época, como por ejemplo Kurt Schneider y Max Scheler (Danzer 2011, Goddemeier 2017, Kessel 2019).

El libro de Hartmann mencionado en $\mathrm{La}$ personalidad y el carácter es Ethik (Hartmann 1926), uno de los más importantes sobre el tema escritos en el siglo XX (Vélez León 2016).

Ethik es un trabajo monumental tanto en sus

8 Hartmann comenzó estudiando medicina, pero dejó esta área del saber para estudiar filosofía. dimensiones (más de 800 páginas) como en su propósito, pues se proponía abarcar todo lo que en Occidente se entendía bajo el término deética (Vélez León 2012). En esta obra, como en casi todas del gran pensador alemán, encontramos una gran riqueza en planteamientos, particular sutileza en el análisis de complejos problemas de la conducta humana, precisión a la par que fuerza argumentativa y propuestas sugestivas. Todo esto en un estilo sobrio, parco, directo pero no carente de elegancia. ${ }^{9}$ Además,

9 "Los libros de Hartmann se leen, sin prescindencia de su profundidad y sin dejar de lado la vastedad de sus horizontes temáticos, de modo fácil, y a lo largo de muchos párrafos el lector permanece subyugado. Están escritos en un lenguaje

Tabla 3: Estructura del libro La personalidad y el carácter

\begin{tabular}{|c|c|c|}
\hline Capitulo & Col & \\
\hline & 1. & Definición y limitación fenomenológica; \\
\hline & 2. & Estructura general de la personalidad; \\
\hline & 3. & Evolución de la personalidad; \\
\hline LA PERSONALIDAD NORMAL & 4. & Dinámica de la personalidad y formación del carácter; \\
\hline & 5. & Tipos de carácter; \\
\hline & 6. & Factores genéticos y condiciones de integración; y, \\
\hline & 7. & Caracterografía \\
\hline & 1. & Antecedentes; \\
\hline & 2. & Circunscripción del concepto; \\
\hline & 3. & Aspecto descriptivo y estructural; \\
\hline & 4. & Variedad de formas; \\
\hline I A PER SONAI IDAD ANORMAI & 5. & Predisposición hereditaria; \\
\hline LA I LNDUNALIDAD ANUTIVAL & 6. & Constitución; \\
\hline & 7. & Influencia del medio; \\
\hline & 8. & Porte personal; \\
\hline & 9. & Relación con las enfermedades mentales; \\
\hline & 10. & Resumen \\
\hline & 1. & Concepto de cultura \\
\hline & 2. & El espíritu de nuestra época; \\
\hline LA PERSONALIDAD Y LA CRISIS & 3. & Crisis actual de la cultura \\
\hline 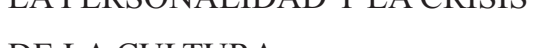 & 4. & Aceleración discordante en el desarrollo; \\
\hline DE LACULIUKA & 5. & Distanciamiento entre el adulto y el niño \\
\hline & 6. & El niño, fontanar de cultura \\
\hline & 7. & Conclusión \\
\hline
\end{tabular}


precisamente en este libro, así como en Das Problem des geistiges Seins (Hartmann 1932) una obra asimismo monumental, Hartmann trata in extenso temas psicológicos.

$\mathrm{Su}$ teoría de los estratos del mundo real, el orgánico, el psicológico y el espiritual (que elaborara en los años 30), así como los principios que formulara para establecer las relaciones entre ellos (el superior se basa siempre en el inferior, es menos fuerte que el anterior, pero posee libertad de desarrollo) fueron muy bien recibidas en los círculos alemanes que estudiaban la personalidad, y algunos neurocientistas las encuentran de gran interés (Jung 1922).

Los años no transcurren en vano. El paso del tiempo ha cobrado su tributo con respecto a La personalidad y el carácter. La psicología de la personalidad es hoy estudiada con procedimientos y parámetros lejanos a los que predominaban en la época en la cual Delgado escribe su libro (Dumont 2010). Y los teóricos de la personalidad son también otros: pocos leen hoy a Spranger y pocos también los que frecuentan las obras de Jung.

$Y$, sin embargo, las descripciones que hace Delgado de las tipologías que hemos mencionado, y las reflexiones que formula en torno a la personalidad, su estructura, y al carácter conservan actualidad, pues se trata de conceptos en los cuales lo permanente se mezcla con lo cambiante, lo de hoy se integra a lo de siempre, y eso hace que a pesar del tiempo transcurrido podamos reconocer elementos del pasado en la psicología de la personalidad de hoy.

Así, si bien el término carácter ha sido casi expulsado del campo de la psicología después

claro, elegante y sin embargo directo, que apunta a la precisión conceptual y es ajeno a manierismos y construcciones artificiosas" (p. 49), así califica Harich (2000) a los libros de este pensador. de que McDougall (1932) pronunciara la "sentencia de muerte" contra él, conserva plena actualidad la idea (que Delgado defiende) de que la personalidad y el desarrollo de la persona no solo dependen de factores internos como el temperamento, sino también hasta cierto punto de procesos de deliberada modificación de la conducta por medio de la autoeducación y del seguimiento de modelos de comportamiento. Más aún: se revela como moderna.

\section{CONCLUSiOnes}

Psicología y La personalidad y el carácter constituyen las expresiones más claras y sistemáticas del interés de Honorio Delgado por la cosa psicológica.

Destacamos lo de expresiones más claras porque lo cierto es que a lo largo de toda su actividad publicista iniciada el primer día del año 1915 y continuada hasta el fin de sus días en noviembre de 1969, el psiquiatra peruano abordó repetidamente temas psicológicos.

Así es. Nos hemos referido a dos obras, pero encontramos muchos trabajos más, artículos, capítulos de libros, ensayos, libros mismos, en que Delgado trata de temas psicológicos. Comenzando por su tesis doctoral en ciencias, pasando por Algunos aspectos de la psicología del niño (Delgado 1922) y La formación espiritual del individuo (Delgado 1933), para concluir con Contribuciones a la psicología y a la psicopatología (Delgado 1962), libro jubilar con motivo de sus 70 años, en el cual cinco de los siete trabajos suyos incluidos tratan de la psicología, ciertamente en su vinculación con la psicopatología, a saber: "En torno al alma ajena", "Psicología general y psicopatología de la voluntad", "Psicología general y psicopatología de las tendencias instintivas", "Psicología general y psicopatología de la 
consciencia del yo", y "Psicología general y psicopatología de la inteligencia".

La lectura de todos estos trabajos, publicados a lo largo de muchos años ${ }^{10}$, nos permite inscribir de modo inequívoco a Honorio Delgado en la línea de la psicología fenomenológica, corriente filosófica de gran significado, con nombres como los de Husserl y Rickert que aún hoy resuenan y cuyas obras siguen siendo leídas, la fenomenología adquirió también carta de ciudadanía entre psiquiatras y psicólogos así como entre científicos sociales. La mejor demostración de eso la tenemos en el gran aporte conceptual de Max Weber, figura central del pensamiento sociológico del siglo XX. En la psiquiatría y la psicología la figura más representativa fue Karl Jaspers (1883-1969), cuya Allgemeine Psychopathologie [Psicopatologia general, Jaspers 1913] fue celebrada en el centenario de su publicación aún no hace mucho.

Otro importante propulsor fue Max Scheler (1874-1928), al cual Delgado se refiere de manera detenida en La formación espiritual del individuo (Delgado 1943), y cuyo nombre también aparece entre los más citados en Psicología. Personalidad fulgurante, pensador penetrante aunque poco sistemático y proclive al desorden, Scheler incursionó con lúcidas intuiciones en algunos de los más intrincados meandros del psiquismo humano. El resentimiento fue uno de los temas que con mayor lucidez abordó (Scheler 1912), pero también otros fenómenos psicológicos de peso relativamente menor pero igualmente dignos de estudio: la vergüenza por ejemplo (Scheler 1957).

$10 \mathrm{Al}$ comenzar este trabajo hemos hecho referencia a estos trabajos. Solo debemos agregar que "En torno al alma ajena" se publicó en 1953 (Delgado 1953).
Sus ideas, unidas a su profundo conocimiento de la psicología de su época y también del psicoanálisis (Scheidt 1986), explican el atractivo y la influencia de este pensador entre numerosos psiquiatras y psicólogos. Uno de ellos fue Honorio Delgado.

Algunos de los críticos del psiquiatra peruano cuestionan el enfoque fenomenológico y se expresan en términos muy escépticos acerca de él. Lo que no se entiende es que la fenomenología en el campo de la psicología y la psicopatología ha dado valiosos frutos. Fue la fenomenología la que, a través de la obra seminal de Karl Jaspers (1913), sentó las bases de la moderna psicopatología. Y se olvida, de otro lado, que muchos de los problemas del mundo moderno, en su desafiante complejidad, en su naturaleza inédita, en su significación social, solo pueden ser abordados desde una perspectiva fenomenológica. Por eso es "que no parece que haya llegado el momento de que se tenga que renunciar a [el método fenomenológico] de forma absoluta" (Jarne Esparcia \& Requena Varón 2015: 50).

La crítica, asimismo escuchada, de que la de Delgado es una psicología y hasta una psiquiatría con "demasiada filosofía", es tal vez la más equivocada porque "presupuestos filosóficos sobre la naturaleza humana se encuentran en la disciplina que se ocupa de los asuntos de los hombres y las mujeres y, en particular, si se trata de asuntos psiquiátricos y psicológicos" (Pérez Álvarez 2012: 21).

Como todo método, como todo acercamiento al ser humano, la fenomenología tiene sus limitaciones. Como los tienen otras formas de entender la condición del hombre. Sin embargo, el interés de la fenomenología por la experiencia de primera persona, "tal como las personas viven y experimentan lo que les pasa" (Pérez Álvarez 2012:173), la presenta como la 
mayor alternativa a la concepción nosológica y neurobiológica de la problemática psicológica.

Concluimos. Psicología y La personalidad y el carácter, concluimos, son solo hitos del interés de Delgado por la psicología, un interés permanente y con resultados fructuosos, porque así como se puede decir que Honorato de Balzac con sus más de 90 novelas, es en sí mismo toda una literatura (Silva-Santisteban 2017), igual se puede sostener que Honorio Delgado es en sí mismo toda una psicología: la psicología general, la psicología del desarrollo, la psicología social, la psicología de la creatividad, la posibilidad del saber psicológico, todo eso y mucho más está en su obra.

\section{ReFerencias Bibliográficas}

1. Adler, A. (1993). El carácter neurótico. Barcelona: Paidós Ibérica.Alarcón, R.(2000).HistoriadelapsicologíaenelPerú.Dela Colonia a la República. Lima: Universidad Ricardo Palma.

2. Alarcón-Guzmán, R. (1982). Vigencia del pensamiento de Honorio Delgado en la psiquiatría contemporánea. Revista de Neuro-psiquiatría, 45, 127-151.

3. Alarcón-Guzmán, R. (2008). Honorio Delgado (1892-1969). En: Cateriano Bellido, P., comp., Veinte peruanos del siglo XX, Lima, Universidad Peruana de Ciencias Aplicadas, 87-102.

4. Alarcón Guzmán, R. D. (2014). Don Oscar (Del) Pino Galarza y la Revista de Neuro-psiquiatría: recordando a nuestro orfebre. Revista de Neuro-psiquiatría, 77, 201-206.

5. Álvaro, L. C. (2016). Swann's way: Proust as a neurobiologist and neurologist. Neurosciences and History, 4, (1), 21-33.

6. Allport, G.W. (1937). Personality: a psychological interpretation. New York: Holt.

7. Ben Plotkin, M. \& Ruperthuz Honorato, M. (2017). Estimado Doctor Freud. Una historia cultural del psicoanálisis en América Latina. Buenos Aires: Edhasa.

8. Binswanger, L. (1922) Einführung in die Probleme der Allgemeinen Psychologie. Berlín: Julius Springer.

9. Blumenfeld, W.(1946). Introducción ala psicología experimental. Lima: Cultura Antártica.

10. Bordelois, I. (2016). La escucha del cuerpo. Puente entre la salud y las palabras. Buenos Aires: Libros del Zorzal.

11. Chiappo, L. (1957). La psicología de Honorio Delgado. En: Homenaje a Honorio Delgado en su 65. aniversario, Lima, Tipografía Peruana, 82-106.

12. Chiappo, L. (1992). La concepción del hombre en Honorio Delgado. Apuntes (Lima), 31,55-62.

13. Chiappo, L. (1994). Presencia espiritual de Honorio Delgado: maestro de vida superior. Lima: Universidad Peruana Cayetano Heredia.

14. Cicovacki, P. (2014). The analysis of wonder. An introduction to philosophy of Nicolai Hartmann. New York: Bloomsbury.

15. Danzer, G.(2011). Wersind wir?AufdersuchenachderFormeldes Menschen. Anthropologie für das 21. Jahrhundert - Mediziner, Philosophen und ihre Theorien, Ideen und Konzepte. Berlín: Springer.

16. Delgado, H. (1915). El psicoanálisis. El Comercio, edición del 1 de enero.

17. Delgado, H. (1922). Algunos aspectos de la psicología del niño. Lima: La Opinión Nacional.

18. Delgado,H.(1923). Rehumanización dela cultura científica porla psicología. Lima: Universidad Nacional Mayor de San Marcos, tesis para optar el grado de Doctor en Ciencias.

19. Delgado,H.(1933).Laformaciónespiritualdelindividuo.Lima:La Librería Peruana.

20. Delgado, H. (1935). Psicología general y psicopatología de la percepción. Actualidad Médica Peruana, 1, 231-248.

21. Delgado, H. (1936a). Psicología general y psicopatología del pensamiento y la imaginación. Actualidad Médica Peruana, 2 (1), 3-37.

22. Delgado, H. (1936b). Psicología general y psicopatología del sentimiento. Actualidad Médica Peruana, 2 (5), 199-219.

23. Delgado, H. (1938a). Psicología general y psicopatología de las tendencias instintivas. Revista de Neuro-psiquiatría, 1(3), 255-353.

24. Delgado, H. (1938b). Psicología general y psicopatología de la conciencia del yo. Actualidad Médica Peruana, 3 (11), 473-489.

25. Delgado, H. (1939). Psicología general y psicopatología de la voluntad. Revista de Neuro-psiquiatría, 2 (1), 1-61.

26. Delgado, H. (1940). Psicología general y psicopatología de la inteligencia. Revista de Neuro-psiquiatría, 3 (3), 291-354.

27. Delgado, H. (1943). La personalidad y el carácter. Lima [5ta. edición, Universidad Peruana Cayetano Heredia, 2006].

28. Delgado, H. (1953a). Curso de psiquiatría. Lima: Imprenta Santa María.

29. Delgado, H. (1953b). En torno al alma ajena. Letras Peruanas, 3 (9), $1-3$ y 26.

30. Delgado, H. (1955). La objetividad de los valores frente al subjetivismo existencialista. Philosophia. Anuario de Filosofía, 2021, 3-10.

31. Delgado,H.(1956).NicolaiHartmannyelreinodelespíritu.Lima: Lumen.

32. Delgado, H. (1961). De la cultura y sus artífices. Madrid: Aguilar.

33. Delgado, H. (1962). Contribuciones a la psicología y a la psicopatología. Lima: Peri Psyches Ediciones.

34. Delgado, H. \& Iberico, M. (1933). Psicología. Lima.

35. Díaz Díaz, G. \& Santos Escudero, C., eds. (1982). Bibliografía filosófica hispánica (1901-1970). Madrid: Consejo Superior de Investigaciones Científicas - Instituto de Filosofía Luis Vives, Departamento de Filosofía Española.

36. Dumont, F. (2010). A history of personality psychology. Theory, science, and research from Hellenism to the Twenty-first century. Cambridge: Cambridge University Press.

37. Erikson, E. H. (1950). Childhood and society. New York: Norton. Fahrenberg, J. (2015). Theoretische Psychologie. Eine Systematik der Kontroversen. Lengerich: Pabst Science Publisher.

38. Freud, S. (1968). Proyecto de una psicología para neurólogos. En: Obras completas, Madrid, Biblioteca Nueva, vol. 3, 883-968.

39. Garrido, M.; Valdés, L. M. \& Arenas, L. coords. (2019). El legado filosófico y científico del siglo XX. Madrid: Cátedra.

40. Geuter, U. (1988). Die Professionalisierung der deutschen Psychologie im Nationalsozialismus. Frankfurt: Suhrkamp.

41. Gigerenzer, G. (2008). Decisiones instintivas. La inteligencia del inconsciente. Barcelona: Ariel. 
42. Glynos, J. \& Stavrakakis, Y. (2001). Postures and impostures: On Lacan's style and use of mathematical science. American Imago, 58 (3), 685-706.

43. Goddemeier, C. (2017). Unverzichtbare Psychopathologie. Deutsches Ärzteblatt, Heft 11, A, noviembre, 534-535.

44. Harich, W. (2000). Nicolai Hartmann. Leben, Werk, Wirkung. Würzburg: Königshausen \& Neumann (editado por M. Morgenstern).

45. Hartmann, N. (1926). Ethik. Berlín - Leipzig: Walter de Gruyter [Ética, Madrid, Encuentro, 2011, traducción de J. Palacios].

46. Hartmann, N. (1932). Das Problem des geistiges Seins. Untersuchungen zur Grundlegung der Geschichtsphilosophie und der Geisteswissenschaften. Berlín: Walter de Gruyter.

47. Hernández Ortiz, A. (2014). El papel del “Proyecto de psicología en la obra freudiana". http://heortiz.net/psicoanalisis/ Proyecto.pdf

48. Hogarth, R. M. (2010). Intuition: a challenge for psychological research on decision making. Psychological Inquiry, 21, 338-353.

49. Iberico, M. (1913). Carácter. Lima: Imprenta Centro Editorial Beytia [un año antes, mecanografiada, presentada como tesis para optar el grado de bachiller en la Facultad de Filosofía y Letras de la Universidad de San Marcos].

50. Iberico, M. (1916). La filosofía de Enrique Bergson. Lima: Imprenta Sanmartí Cía. [presentada como tesis doctoral ante la Facultad de Filosofía y Letras de la Universidad de San Marcos el mismo año].

51. James, W. (1890). The principles of psychology. New York: Henry Holt and Company, 2 vols.

52. Jarne Esparcia, A. \& Requena Varón, E. (2015). Evolución de los conceptos en psicopatología. En: Jarne Esparcia, A. Talarn Caparrós, A., comps., Manual de psicopatología clínica, Barcelona, Herder, 29-54.

53. Jaspers, K. (1913). Allgemeine Psychopathologie. Ein Laitfaden für Studierende, Ärzte und Psychologen. Berlín: Springer.

54. Jaspers, W. (1919). Psychologie der Weltanschauungen. Berlín: Springer.

55. Jung, R. (1992). Some European neuroscientists: a personal tribute. En: Worden, F. G.; Swazey, J. P. \& Adelman, G. eds., The neurosciences: paths of discovery. I, Boston, Birkhäuser, 477-511.

56. Kahnemann, D. (2012). Pensar rápido, pensar despacio. Barcelona: Debate.

57. Kessel, T. (2019). Nicolai Hartmann und die philosophische Psychologie.

"Wie

ist allgemeine philosophische Psychologie möglich? En: Kessel, T., ed., Philosophische Psychologie um 1900, Wuppertal, J. B. Metzler, 215-231.

58. Kluy, A. (2019). Alfred Adler. Die Vermessung der menschlichen Psyche. Biographie. Munich: Deutsche Verlags-Anstalt.

59. Köhler, W. (1921). Intelligenzprüfungen an Menschenaffen. Berlín: Springer.

60. Kraepelin, E. (1883). Compendium der Psychiatrie. Leipzig: Ambrosius Barth.

61. Lehrer, J. (2010). Proust y la neurociencia. Una visión de ocho artistas fundamentales de la modernidad. Madrid: Paidós.

62. León, R. (2018). Los inicios del psicoanálisis en Perú: Honorio Delgado y El Comercio, 1915. Paideia XXI. Revista de la Escuela de Postgrado (Universidad Ricardo Palma, Lima), 6 (7), 33-51.

63. Lolas Spteke, F. (1995). Apología del texto de estudio, literatura terciaria de la ciencia. Santiago (Chile): Universidad de Chile.

64. Macho, S. (2016). Wissenschaft und Pseudowissenschaft in der Psychologie. Berna: Hogrefe.

65. Mariátegui, J. (1989a). La psiquiatría en el Perú. En: Mariátegui, J., ed., La psiquiatría en América Latina, Buenos Aires, Losada,
163-182.

66. Mariátegui, J. (1989b). Sigmund Freud en el Perú. Notas para la historia del movimiento psicoanalítico en Iberoamérica. En: Delgado, H., Freud y el psicoanálisis. Escritos y testimonio, Lima, Universidad Peruana Cayetano Heredia, 15-65.

67. McDougall, W. (1932). Of the words character and personality. Character \& Personality; A Quarterly for Psychodiagnostic \& Allied Studies, 1, 3-16

68. Murdoch, I. (2018). La salvación por las palabras. ¿Puede la literatura curarnos de los males de la filosofía? Madrid: Siruela.

69. Navalles Gómez, J. (2009). Retrospectivas disciplinares: tres historias cortas de Wilhelm Wundt. Athenea Digital, 15, 135147 https: / / www.raco.cat/index.php/Athenea/article/view/

130693.

70. Nicholson, I. A. M. (1998). Gordon Allport character, and the "culture of personality", 1897-1937. History of Psychology, 1 (1), 52-68.

71. Parrat-Dayan, S. (2010). Comunicación personal.

72. PérezÁlvarez,M.(2012).Las raíces dela psicopatología moderna. La melancolía y la esquizofrenia. Madrid: Pirámide.

73. Peters, U. H. (1992). Psychiatrie im Exil. Die Emigration der dynamischen Psychiatrie aus Deutschland 1933-1939. Düsseldorf: Kupka Verlag.

74. Peters, U. H. (2010). El siglo de la psiquiatría alemana: ¿Cómo empezó y cómo finalizó? Persona (Universidad de Lima), 13, 99-110.

75. Piccolino, M. (2019). Literature and neurosciences: the temps perdu. Between Hermann von Helmholtz and Marcel Proust. En:Colombo,B.,ed.,Brainandart.Fromaestheticstotherapeutics, Cham (Suiza), Springer Nature, 139-152.

76. Quian Quiroga, R. (2012). Borges and memory. Encounters with the human brain. Cambridge MA: MIT.

77. Ramos-Arenas, J. (2018). La autonomía del lenguaje psicológico. En:Gutiérrez, G.,ed., Teoríasen psicología.Integracióny elfuturo de la disciplina, Bogotá, Manual Moderno, 124-139.

78. Ramos Rau, D. (2006). Mariano Iberico Rodríguez. Pueblo Continente (Trujillo), 17 (2), 259-270.

79. Rey de Castro, A. (1989). Las cartas de Sigmund Freud a Honorio Delgado. En: Delgado, H., Freud y el psicoanálisis. Escritos y testimonio, Lima, Universidad Peruana Cayetano Heredia, 507-569.

80. Reyes Álvarez, C. (2014). Bibliografía de Mariano Iberico. Solar, 10 (2), 121-139.

81. Russo Delgado, J. (1962). Lecciones de psicología general. Lima: Universidad Nacional Mayor de San Marcos.

82. Scheidt, C. E. (1987). Die Rezeption der Psychoanalyse in der deutschsprachigen Philosophie vor 1940. Frankfurt: Suhrkamp.

83. Scheler, M. (1912). Über Ressentiment und moralisches Werturteil: ein Beitrag zur Pathologie der Kultur. Zeitschrift für Psychopathologie, 1 (2-3), 268-368 [El resentimiento en la moral, Madrid, Caparrós, 1998]

84. Scheler, M. (1957). Über Scham und Schamgefühl. En: Gesammelte Werke (vol. 10: Schriften aus dem Nachlass, vol. 1: Zur Ethik und Erkenntnislehre), Berna, Francke 67-154 [orig. en alemán 1913; Sobre el pudor y el sentimiento de vergüenza, Salamanca, Sígueme, 2004].

85. Silva-Santisteban, R. (2012). Los hijos del limo y del fuego. Antología poética del romanticismo francés (vol, 2). Lima, Alastor Editores, Academia Peruana de la Lengua.

86. Stahnisch, F. W. \& Russell, G. A., eds. (2018). Forced migration in the history of 20th century neuroscience and psychiatry. New perspectives. Londres: Routledge. 
87. Stock, A. \& Schneider, W., eds. (2020). Die ersten Institute für PsychologieimdeutschsprachigenRaum. IhreGeschichtevonder Entstehung bis zur Gegenwart. Gotinga: Hogrefe.

88. Vélez León, P. (2012). Nicolai Hartmann: una apostilla bibliográfica a propósito de la traducción de su Ética. Disputatio. Philosophical Research Bulletin, 1 (2), 113-129.

89. Vélez León, P. (2016). Un perfil intelectual de Nicolai Hartmann (1882-1950). Parte I. Disputatio. Philosophical Research Bulletin, 5 (6), 457-538.

90. Vincent, B. (2019). Lacan. Style des écrits. Lormont: Éditions Le Bord de L'Eau.

91. Wundt, W. (1874). Grundzüge der Physiologischen Psychologie. Leipzig: WilhelmEngelmann.
92. Wundt, W. (1900-1920). Völkerpsychologie. Eine Untersuchung derEntwicklungsgesetzevonSprache,MythusundSitte.Leipzig: Alfred Kröner Verlag [vol. 1, Die Sprache -Erster Teil-, 1900; vol. 2, Die Sprache -Zweiter Teil-, 1900; vol. 3, Die Kunst, 1905; vol. 4, Mythus und Religion -Erster Teil-, 1905;vol. 5, Mythus und Religion-Zweiter Teil-, 1906; vol. 6, Mythus und Religion-Dritter Teil-, 1909; vol. 7, Die Gesellschaft -Erster Teil-, 1917; vol. 8, Die Gesellschaft -Zweiter Teil-,1917; vol. 9, Das Recht, 1918; vol. 10,

Kultur und Geschichte, 1920]

\section{CORRESPONDENCIA:}

Ramón León

rld310850@yahoo.com.mx

FECHA DE RECEPCIÓN: 24-06-2020.

FECHA DE ACEPTACIÓN: 21-07-2020. 